$\xi=-1$

\title{
Development and Design Of 8x1 Micro Strip Antenna Array for Military/Satellite Communication
}

\author{
${ }_{1,}^{1}$ A. Mary Joy Kinol, ${ }^{2}$ A. Sahaya Anselin nisha \\ ${ }^{1}$ Research Scholar, Sathyabama Institute of Science and Technology, Chennai, India. \\ ${ }^{2}$ Professor, Sathyabama Institute of Science and Technology, Chennai, India. \\ *Corresponding author's Email: alphonse.kinol@gmail.com
}

\begin{abstract}
Antenna design has become as established field of research in recent years. The most important feature of MPA is low cost, low profile and single layer configuration. The frequency band at which the patch antenna operates is $12-1 \mathrm{GHz}$ and antenna array are fielded by Microstrip field line incorporated with $50 \Omega$ impedance. In order to achieve enhancement in gain, directivity, bandwidth and return loss Quarter wave transformer and power divider are used. Microstrip patch antenna, employed with highly reflective properties is presented with the results of modeling, design and simulation. To illustrate this techniques a KU band $2 \times 1,4 \times 1,8 \times 1$ antenna array integrated with series corporate feeding network are designed and simulated. The maximum gain of $14.56 \mathrm{~dB}$ at $10 \mathrm{GHz}$, the impedance beam width is $86.72 \%$ and $99 \%$ efficiency is arrived using this technique. Maximum radiation pattern is achieved by using low dielectric substrate of RT-DURROID. The design is verified using HFSS software, used to simulate the antenna array.
\end{abstract}

Keywords. Array antenna, Reflection Co- efficient, gain, impedance bandwidth, VSWR, Beam width

\section{Introduction}

With rising framework design of millimeter wave, for instance, future $5 \mathrm{G}$ interchanges and high-goals distinguishing proof, unique interests are coordinated toward different multifunctional planar incorporated reception apparatuses. There is in an expanding interest for $\mathrm{Ku}$ band satellite telecom and correspondence frameworks on portable stages. Conventional systems for encouraging smaller scale strip radio wires are the immediate contactsustains where the feeder line like a miniaturized scale strip is associated straightforwardly to the fix [1]. A prominent variation of these is the test coupled-feed that abstains from infringing substrate space by associating from the underside of the ground plane utilizing a coaxial test [2]. Nearness or electromagneticallycoupled feeds make no longer the need of an immediate intersection [3]. In this situation, coupling happens by means of bordering fields from the end side of a smaller scale strip feeder or the line might be enveloped between the fix and ground plane. The transmission and gathering of reception apparatus exhibit for versatile satellite correspondence frameworks was point by point in [4],but the size and stature of recieving wire were Gap coupled field transmits and get radio wire cluster for portable satellite correspondence frameworks was itemized in [4], however the radio wire size and tallness were nearly extensive for car housetop reason. Arrangement sustained space coupled recieving wire exhibit was composed in [5] over a little bit of the downlink band (11.812.2 GHz).To end up cognizant such functionalities, radio wires having low crosstalk between various polarizations are required. Or the consequences will be severe, the primary highlights of these frameworks can without much of a stretch be lost. The coveted radiation conduct can be accomplished through by making the arrangement among reception apparatuses and encouraging layer to a great degree exact. The other conceivable nourishing system for single radiators is substrate-coordinated waveguides
(SIWs) with transmitting spaces [6] a further radio wire cluster approach make utilization of lattice reception apparatuses [8], which are imprinted on one side of the substrate. The opposite side is utilized as a ground plane. Through VIAs sub exhibits are bolstered and a characteristic plentifulness decreasing heads to a side flap level (SLL) of $-13.5 \mathrm{~dB}$ [8]. The surface mass of SIWs are generally expansive and it envelops the entire of impression underneath the fix, which thusly make it hard to assemble two symmetrical SIWs for double polarizations like the small scale strip encouraged partner [9] by thinking about the geometrical confinement. By changing the way of excitation a flexible polarization was presented, which makes it more helpful for milli meterwave activities [11]. A polarization-customizable cluster radio wire was utilized dependent on a miniaturized scale strip nourishing system [17] for gain change. The fundamental thought of radio wire exhibit is utilized to augment the gain and to limit the side projections. $3 \times 3$ reception apparatus cluster was intended to accomplish greatest increase $(17.29 \mathrm{~dB})$ with VSWR esteem 0.7807 and return misfortune 13.33[18]. Wide band remote application CPW nourishing systems are joined to accomplish the recuperated execution [19] and $\mathrm{Ku}$ and $\mathrm{K}$ band importance. Focusing on multiband task, three symmetrical triangle spaces in left, right and upper edge correspondingly, and two little triangular openings are jutting the two sides of the feed line [20].

\section{Antenna Design and Innovation}

Multi biometric systems [4] are used to improve the reliability through multiple sources of information. Antenna element design starting from system specifications is detailed in Section 2. Various feed network design of antenna array in Section 3. Finally, conclusions are presented in Section 4. 


\subsection{Single-Element Rectangular micro strip Patch Antenna}

The single element rectangular micro strip patch antenna is designed using FR4 substrate with dielectric permittivity of $\varepsilon \mathrm{r}=4.4$ and loss tangent of 0.02 and it occupies $22.5 \times 29.33 \times 2.2 \mathrm{~mm}$. In order to achieve to reduce the size of the antenna FR4 substrate is mainly preferred. The bottom side is covered with a partial conducting ground plane and the top side of the substrate is photo etched witha rectangular shaped radiating patch. Patch of the antenna calculated by using the formulas mentioned in [2].

Width of Rectangular Patch is calculated using equation.

$$
w=\frac{c_{0}}{2 f} \sqrt{\frac{2}{\varepsilon_{r}+1}}
$$

$$
\begin{array}{ll}
\mathrm{w} & \text { - Width of the patch } \\
\mathrm{C}_{0} & \text { - Speed of light } \\
\varepsilon_{\mathrm{g}} & \text {-Substrate dielectric constant } \\
\mathrm{f}_{\mathrm{s}} & \text { - Frequency of Resonance }
\end{array}
$$

Length of Rectangular Patch is calculated using equation Effective dielectric constant (areff)

$$
\varepsilon_{r s f^{\prime}}=\frac{\epsilon_{r}+1}{2}+\frac{\epsilon_{r}-1}{2}\left(1+\frac{12 h}{W}\right)^{-\frac{1}{2}}
$$

Fringing effect of patch $\Delta \mathrm{L}$

$$
\Delta L=0.412 h \frac{\left(\varepsilon_{r s f}+0.3\right)\left(\frac{w}{h}+0.264\right)}{\left(\varepsilon_{r s f}-0.258\right)\left(\frac{w}{h}+0.8\right)}
$$

Effective length $\mathrm{L}$ eff

$$
L_{s f t}=\frac{C}{2 f \sqrt{\varepsilon_{r s f}}}
$$

Rectangular Patch length

$$
L=L_{\text {sf }}-2 \Delta
$$

$$
\begin{array}{ll}
\text { ar } & \text { Substrate dielectric constant } \\
\text { h } & \text { - Thickness of substrate material } \\
\text { fr } & \text { - Frequency of Resonance }
\end{array}
$$

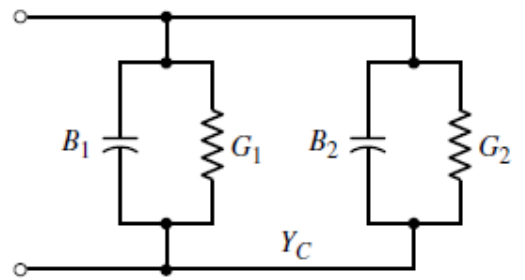

Fig. 1: Equivalent circuit of patch antenna

Table 1: Parameters of proposed Microstrip patch antenna

\begin{tabular}{|c|c|c|}
\hline Antenna Parameters & Values & Units \\
\hline Solution Frequency & 10 & $\mathrm{GHz}$ \\
\hline Patch dimension Along X & 11.85 & $\mathbf{m m}$ \\
\hline Patch dimension Along Y & 9.66 & $\mathbf{m m}$ \\
\hline Substrate Thickness & 0.79 & $\mathbf{m m}$ \\
\hline Substrate dimension Along X & 22.5 & $\mathbf{m m}$ \\
\hline Substrate dimension Along Y & 29.33 & $\mathbf{m m}$ \\
\hline Substrate dielectric constant & 2.2 & - \\
\hline Insert Distance & 2.95 & $\mathbf{m m}$ \\
\hline Inset Gap & 1.217 & $\mathbf{m m}$ \\
\hline Feed Width & 2.434 & $\mathbf{m m}$ \\
\hline Feed Length & $9.13 \mathrm{~S}$ & $\mathbf{m m}$ \\
\hline
\end{tabular}

\section{Micro strip Patch Antenna Design}

\subsection{Single patch Antenna}

The single element Micro strip patch antenna is designed on FR-4 substrate which is having and loss tangent of 0.02 and dielectric permittivity of $\varepsilon r=4.4$ and it occupies $22.5 \times 29.33 \times 1.6 \mathrm{~mm} 3$. The FR-4 substrate is preferred in order to decreases the antenna size. The base is layered with a partial conducting ground plane and top side of the substrate is photo etched with a rectangular shaped radiating patch.

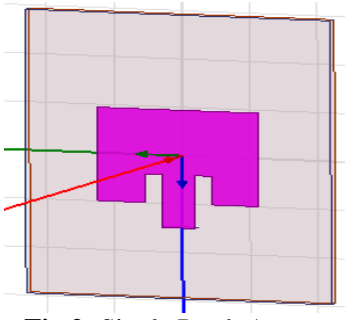

Fig.2: Single Patch Antenna

\subsection{2x1 Micro strip Patch Antenna Design}

To develop the bandwidth $2 \times 1$ micro strip patch antenna design using $\lambda / 2$ spacing between the two patch elements and the same dimensions, a $2 \times 1$ rectangular antenna array is intended. Here series corporate feed techniques are developed using quarter wavelength transformer and $\mathrm{T}$ junction (power divider) excited by source $50 \Omega$.The antenna geometry and its optimized parameters are listed in Table 1. This antenna is simulated in HFSS 3D Electromagnetic computation tool and the essential characteristics are intimate in terms of reflection co efficient, Band width , radiation patterns and VSWR, which are explore in Section III.

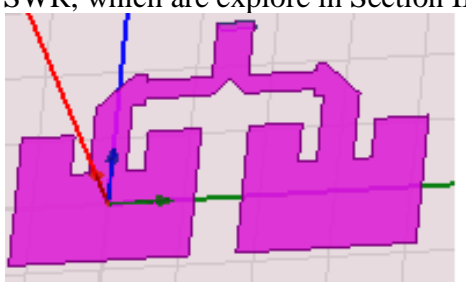

Fig. 3: $42 \times 1$ microstrip patch antenna array

\subsection{4x1 Micro strip Patch Antenna Design}

To maximize the gain of the antenna, consider antenna array. The number of patch increases gives more complicated feeding structure and gets radiation efficiency is small to make the better radiation pattern using series corporate feeding techniques that implemented in 4 element antenna array. This array antenna embrace of a novel corporate feed techniques are implemented to provide directive radiation staging the antenna elements are dispose ata dissociation less than $\lambda$ (wavelength). In the initiate array design the four elements are fed commonly using a T-junction micro strip power divider.

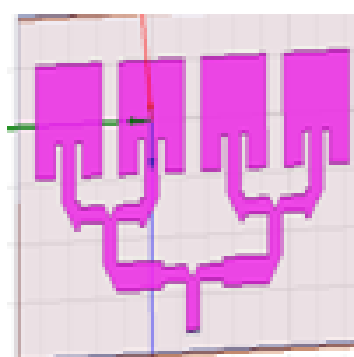

Fig. 4: Geometry of $4 \times 1$ microstrip patch antenna array 


\subsection{8x1 Micro strip Patch Antenna Design}

The four-element patch antenna array with corporate feed is reproducing and organized linearly to form a eight-element antenna array. This array geography contains double levels of feeding which appears to be a binomial tree like formation that uses triple $\mathrm{T}$ junction power dividers. The T-junction power dividers are draft using micro strip to order the universal antenna as a planar structure ultimately of feeding miscellaneous single element patch antennas with exterior power dividers. The initial stage of corporate feed is twisted so that it convince wide band operation and also to decrease un wanted notch levels in the operating band. Moreover, the present 8-element array antenna is incorporated with split-ring resonators lots etched in the ground plane at either side of the main feed line.

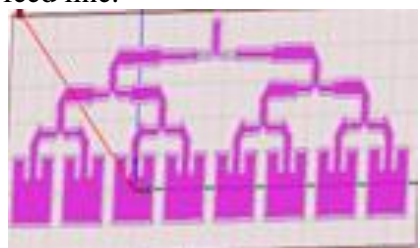

Fig. 5 :Geometry of $8 \times 1$ microstrip patch antenna array

\section{Results and Discussion}

The patch antenna array structure are designed and simulated in ANSYS High Frequency Structure Simulator (HFSS) 17.0. The simulated results in terms of reflection co efficient, radiation patterns, gain, directivity, voltage standing-wave ratio, with neat performance are analyzed in the upcoming section.

\subsection{Return Loss Characteristics of the Proposed Antenna}

The simulated reflection co efficient characteristics of single element $2 \times 1,4 \times 1$ and $8 \times 1$ micro strip patch antenna array are shown in a synthesize plot for comparison. The reflection co efficient performance for various antenna arrays is presented Fig 3 From the plot, we can conclude that with lesser number of radiating elements the number of resonances in the antenna Attribute are lesser and becomes improving when as the number of elements is higher. Also, the level of reflection co efficient is retain in the scale of -20 to $-25 \mathrm{~dB}$ while single element antenna is used and while arraying the radiating elements the reflection co efficient is going to be decreased to a least of $-42.7 \mathrm{~dB}$ observed at $4.18 \mathrm{GHz}$ indicates a good matching with feeder. This indicates the enhancement of gain.

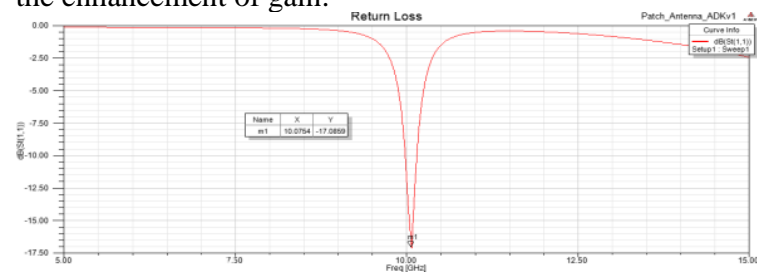

(a)

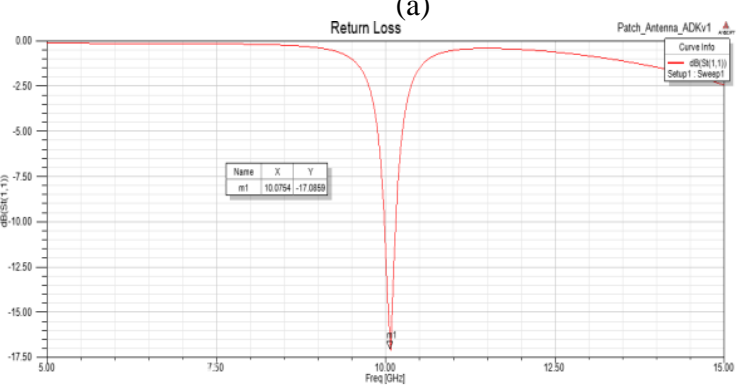

(b)

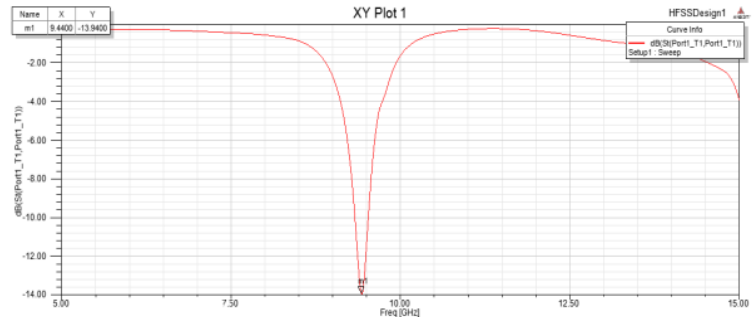

(c)

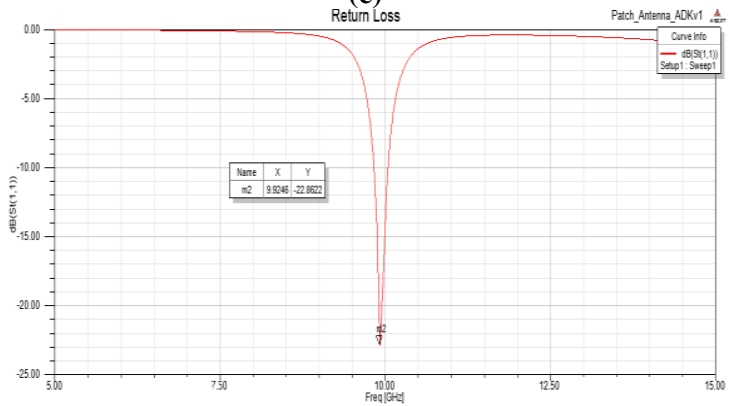

(d)

(a) Single Patch, (b) $2 \times 1$ Patch Antenna Array, (c) $4 \times 1$ Patch Antenna Array, (d ) $8 \times 1$ Patch Antenna Array

Fig. 6: Return Loss for Antenna Array

\subsection{Radiation Performance of Proposed Antenna}

The far-field radiation characteristics of all the various antenna arrays are presented at $\mathrm{X}$ band resonant Frequencies. Radiation patterns are a main character to assess the far-field distribution, gain and directional properties of the antenna. From Fig.7 it can be seen that the single microstrip patch antenna is gives Omnidirectional performances in both $\mathrm{H}$-plane and E-plane .For the $2 \times 1$-element array antenna the simulated far field radiation patterns are plotted as shown in the Fig. 7.The 4-elementarray antenna is showing the good directive radiation characteristics in $\mathrm{X}$ band frequency region. The 8 element antenna array produces a very good radiation pattern it shows in Fig. 7 (d).

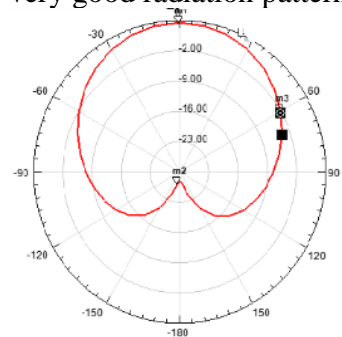

(a)

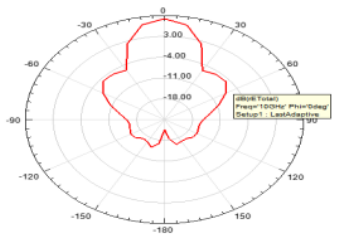

(c)

(a) Single Patch, (b) $2 \times 1$ Patch Antenna Array, (c) $4 \times 1$ Patch Antenna Array , (d ) $8 \times 1$ Patch Antenna Array

Fig. 7: Radiation Pattern for Antenna Array

\subsection{Gain Performance of Proposed Antenna Array}

The gain performance of thesingle patch antenna, $2 \times 1$ and $4 \times 1$ and $8 \times 1$ antenna array that are simulated in HFSS are plotted and shownin Fig. 8. The simulated peak gain of the single patch antenna is $7.18 \mathrm{~dB}$ as shown in Fig 8(a). The simulated peak gain of $2 \times 1$ patch antenna array antenna is $9.86 \mathrm{~dB}$ as shown in Fig $8(\mathrm{~b})$. The simulated peak gain of $4 \times 1$ antenna is 11.64 as shown in Fig 
8 (c). The simulated peak gain of $8 \times 1$ patch antenna array antenna is $14.56 \mathrm{~dB}$ as shown in Fig 8(d). Table III shows a comparison of simulated peak gain of various patch antenna array antenna with reference papers. It can be observed that proposed antenna array provide more gain compared with reference papers as shown in Table III.

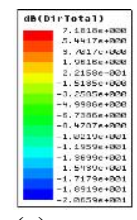

(a)
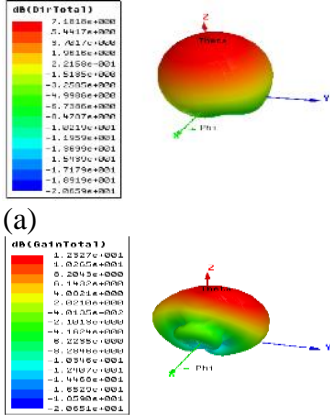

(c)

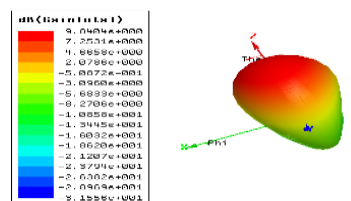

(b)

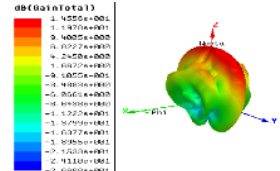

(d)

(a) Single Patch, (b) $2 \times 1$ Patch Antenna Array, (c) $4 \times 1$ Patch Antenna Array , (d ) $8 \times 1$ Patch Antenna Array Fig. 8: Gain of Antenna Array

Table 2. Comparison chart for Single Element, 2-Element array and 4-Element array antennas

\begin{tabular}{|c|c|c|c|c|c|c|}
\hline Antenna Type & Return Loss(dB) & $\operatorname{Gain}(d B)$ & Direc-tivity(dB) & $\begin{array}{c}\text { Resonant } \\
\text { Freq(GHz) }\end{array}$ & $\begin{array}{c}\text { Beamwidth } \\
\text { (dB) }\end{array}$ & Efficiency (\%) \\
\hline $\begin{array}{c}\text { Single } \\
\text { Patch Antenna }\end{array}$ & -22.86 & 7.18 & 7.18 & 9.92 & 77.49 & 97.9 \\
\hline $2 \times 1$ antenna Array & -17.09 & 9.84 & 9.86 & 10.07 & 46.23 & 99.35 \\
\hline $4 \times 1$ antenna Array & -13.94 & 11.64 & 11.65 & 9.64 & 45.59 & 99.5 \\
\hline $8 \times 1$ antenna Array & -21.06 & 14.56 & 14.61 & 10.28 & 5.777 & 98.9 \\
\hline
\end{tabular}

Table 3. Comparative study of proposed work with existing designs

\begin{tabular}{|c|c|c|c|c|c|c|c|}
\hline [Ref.No] & $\begin{array}{l}\text { Antenna Dimen- } \\
\text { sion } \\
(\mathbf{L} \times \mathbf{W} \times \mathbf{h}) \mathbf{m m} 3\end{array}$ & Feeding Techniques & $\varepsilon \mathbf{r}$ & $\begin{array}{c}\text { Operating } \\
\text { Band } \\
\text { (GHz) } \\
\end{array}$ & $\begin{array}{l}\text { No.of ele- } \\
\text { ments }\end{array}$ & $\begin{array}{l}\text { Differentiate with } \\
\text { single element }\end{array}$ & $\begin{array}{c}\text { Peak } \\
\text { Gain }(d B)\end{array}$ \\
\hline [9] & $47 \times 35 \times 1$ & $\begin{array}{l}4: 1 \text { equal power divider with } \\
\text { coaxial feed }\end{array}$ & 4.4 & $2-11$ & 4 & $>3 \mathrm{~dB}$ & $9 \mathrm{~dB}$ \\
\hline$[10]$ & $100 \times 30 \times 1.5$ & $\begin{array}{l}\text { Microstrip line excitation to } \\
\text { central element }\end{array}$ & 4.4 & $3.6-9.6$ & 3 & $1.83 \mathrm{~dB}$ & $4.85 \mathrm{~dB}$ \\
\hline [11] & $320 \times 300 \times 1.6$ & Corporate feed & 4.4 & $2.29-2.67$ & 16 & $5 \mathrm{~dB}$ & NA \\
\hline [12] & $87.2 \times 106 \times 0.8$ & $\begin{array}{c}\text { Corporate feed(Wilkinson } \\
\text { power divider) }\end{array}$ & 2.56 & $3.1-10.6$ & 4 & $>2 \mathrm{~dB}$ & $10.5 \mathrm{~dB}$ \\
\hline$[13]$ & $80 \times 80 \times 1$ & $\begin{array}{l}\text { Slot line transmission with } \\
\text { probe feed }\end{array}$ & 2.2 & $2.35-6.1$ & 4 & $>2 \mathrm{~dB}$ & $7.1 \mathrm{~dB}$ \\
\hline Proposed Work & $22.5 \times 29.33 \times 1.6$ & Series Corporate Feed & 2.2 & $8.5-10$ & 8 & $>2.5 \mathrm{~dB}$ & $14.56 \mathrm{~dB}$ \\
\hline
\end{tabular}




\section{Conclusions}

The design advance to array antenna idea that is implemented for single rectangular patch antenna has increases the directive performance of the antenna which is operating in X band Spectrum. The simulated results like reflection co efficient, radiation pattern, beam width, directivity and gain has shown in fig. Also, the proposed work is differentiate with existing models and showed to be better performance in terms of peak gain improvement and bandwidth enhancement with that of its single element configuration. The proposed array antenna can be include in the devices that supports the standards like downlink-X band Satellite communication , military application WLAN, WiMAX, bands with directive patterns. The proposed antenna is good performance appropriate for the high speed running vehicle detection, vehicular communication applications moving target detection.

\section{References}

[1] K. G. Thomas and M. Sreenivasan, "A simple ultra wideband rectangular printed antenna with band dispensation," IEEE Trans. Antennas Propag., vol. 58, no. 1, pp. 27-34, Jan. 2010.

[2] D. Guha, M. Biswas, and J. Y. Siddiqui, "Harrington's formula extended to determine accurate feed reactance of probe-fed microstrip patches," IEEE Antennas Wireless Propag. Lett., vol. 6, pp. 33-35,

[3] C.-K. Lin and S.-J. Chung, "A compact edge-fed filtering microstrip antenna with $0.2 \mathrm{~dB}$ equal-ripple response," In Proc. 39th Eur.Microw. Conf., Rome, Italy, Sep. 29-Oct. 1, 2009, pp. 378-380

[4] S. Vaccaro, F. Tiezzi, M. F. Rúa, and C. D. G. De Oro, "Kuband low-profile Rx-only and Tx-Rx antennas for mobile satellite communications," in Proc. IEEE Int. Symp. on Phased Array Systems and Technology, 2010, pp. 536-542.

[5] R. Azadegan, "A Ku-band planar antenna array for mobile satellite TV reception with linear polarization," IEEE Trans. Antennas Propag., vol.58, no. 6, pp. 2097-2101, Jun. 2010.

[6] T. Li and W. B. Dou, "Millimetre-wave slotted array antenna based on double-layer substrate integrated waveguide," IET Microw., Antennas Propag., vol. 9, no. 9, pp. 882-888, Jun. 2015.

[7] F. Bauer and W. Menzel, "A $79 \mathrm{GHz}$ microstrip grid array antenna using a laminated waveguide feed in LTCC," in Proc. IEEE Int. Symp. Antennas Propag., Spokane, WA, USA, Jul. 2011, pp. 2067-2070.

[8] G. F. Hamberger, S. Trummer, U. Siart, and T. F. Eibert, “A planar dual polarized microstrip antenna array in

series-parallel feed configuration," in Proc. Loughborough Antennas Propag. Conf., Nov. 2015, pp. 1-4.

[9] C. Chen, J. Shao, S. Meng, G. Fang and H. Yin, "4- element planar array antenna for UWBapplication", J. of Electronics (China), Vol. 31, pp.175-179, Apr. 2014.

[10] W. A. Ali, A. I. Zaki and M. Abdou, "Design and fabrication of rectangular ring monopole array with parasitic elements for UWB applications," Microw. Opt. Technol. Lett., Vol. 58, pp. 2268-2273, Jun.2016.

[11] Y. Jiang, W. Geyi, L. Yang and H. Sun, "Circularly-Polarized Focused Microstrip Antenna Arrays", IEEE Antennas and Wireless Propag. Lett., Vol. 15, pp. 52-55, May. 2015.

[12] Y.-Y. Yang and Q.-X Chu, "Planar 4-element UWB antenna array and time domain characterization", Microw. Opt. Technol. Lett., Vol. 50, pp. 3118-3123, Sep. 2008.

[13] C.-X. Zhang, Y.-Q. Zhuang, X.-K. Zhang, and L. Hu, "An UWB microstrip antenna array with novel corporate-fed structure," Prog. In Electromagn. Res. C, Vol. 52, pp. 7-12, Aug. 2014.

[14] D. Wang, K. B. Ng, C. H. Chan, and H. Wong, "A novel wideband differentially-fed higher-order mode millimeter-wave patch antenna," IEEE Trans. Antennas Propag., vol. 63, no. 2, pp. 466-473, Feb. 2015.

[15] M. H. Awida, S. H. Suleiman, and A. E. Fathy, "Substrateintegrated cavity-backed patch arrays: A low-cost approach for bandwidth enhancement," IEEE Trans.
[16] Q. Xue, S. W. Liao, and J. H. Xu, "A differentially-driven dual polarized magneto-electric dipole antenna," IEEE Trans. Antennas Propag., vol. 61, no. 1, pp. 425-430, Jan. 2013.

[17] T. Mikulasek, A. Georgiadis, A. Collado, and J. Lacik, " $2 \times 2$ microstrip patch antenna array fed by substrate integrated waveguide for radar applications, " IEEE Antennas Wireless Propag. Lett., vol. 12, pp. 1287-1290, 2013.

[18] J. Rossello, F. Mira, A. Collado, and A. Georgiadis, "Substrate integrated waveguide aperture coupled patch antenna array for $24 \mathrm{GHz}$ wireless backhaul and radar applications," in Proc. IEEE Antenna Meas. Appl. Conf. (CAMA), Nov. 2014, pp. 1-2.

[19] S. Li, J. Gao, X. Cao, Z. Zhao, and D. Zhang, "Broadband and high isolation dual-polarized microstrip antenna with low radar cross section," IEEE Antennas Wireless Propag. Lett., vol. 13, pp. 1413-1416, 2014

[20] Y.-J. Chi and F.-C. Chen, "60-GHz polarization-adjustable antenna arrays," IEEE Trans. Antennas Propag., vol. 63, no. 7, pp. 2887-2894, Jul. 2015 